\title{
The emotional memory effect: Differential processing or item distinctiveness?
}

\author{
Stephen R. Schmidt ANd Bonnie SAARI \\ Middle Tennessee State University, Murfreesboro, Tennessee
}

\begin{abstract}
A color-naming task was followed by incidental free recall to investigate how emotional words affect attention and memory. We compared taboo, nonthreatening negative-affect, and neutral words across three experiments. As compared with neutral words, taboo words led to longer color-naming times and better memory in both within- and between-subjects designs. Color naming of negative-emotion nontaboo words was slower than color naming of neutral words only during block presentation and at relatively short interstimulus intervals (ISIs). The nontaboo emotion words were remembered better than neutral words following blocked and random presentation and at both long and short ISIs, but only in mixed-list designs. Our results support multifactor theories of the effects of emotion on attention and memory. As compared with neutral words, threatening stimuli received increased attention, poststimulus elaboration, and benefit from item distinctiveness, whereas nonthreatening emotional stimuli benefited only from increased item distinctiveness.
\end{abstract}

The emotional response associated with an experience has a large impact on memory for that experience. Emotional narratives are remembered better than comparable neutral narratives (Laney, Campbell, Heuer, \& Reisberg, 2004), a series of emotional slides is better remembered than a neutral series (Heuer \& Reisberg, 1990), emotional words are remembered better than neutral words (Kleinsmith \& Kaplan, 1963), and emotional life experiences may lead to detailed flashbulb-like memories (Brown $\&$ Kulik, 1977). There are numerous theories to explain the impact of emotion on memory, including the attentionnarrowing hypothesis (Easterbrook, 1959), Christianson's (1992a, 1992b) two-stage model, and most recently, MacKay's binding hypothesis (MacKay et al., 2004). These hypotheses share the idea that emotional material captures and holds the attention of the observer, often at the expense of peripheral material. For example, Christianson argued that an emotional event leads to an automatic, preattentive response during which the emotional content of the event is extracted. Later, controlled-elaborative processes lead to increased storage of information central to the event, to the detriment of surrounding information.

However, some have argued that emotional materials are relatively rare or unusual, suggesting that at least some of the memory effects attributed to emotion actually resulted from item distinctiveness (McCloskey, Wible, \& Cohen, 1988; Schmidt, 2002). Similarly, Reisberg and Heuer (2004) argued that emotional materials often (but not always) contain attention magnets that impair the processing of background information. Others have argued that good memory for emotional words is simply an artifact resulting from differences in the ease of organizing emotional and neutral words (Talmi
\& Moscovitch, 2004). The research presented below was designed to investigate how emotion, attention, and item distinctiveness combine to influence memory for words.

Research comparing memory for emotional versus neutral words has a long history. Early researchers investigated paired-associate memory for emotional words, with much of their focus on whether the superior recall of emotional over neutral words required a delayed retention test (Kleinsmith \& Kaplan, 1963, 1964; Maltzman, Kantor, \& Langdon, 1966). However, experimental design emerged as a moderating factor in the influence of emotion on memory (Walker \& Tarte, 1963). Most researchers employed heterogeneous, or mixed, lists of emotional and neutral words. When memory for a homogeneous list of emotional words is compared with that for a list of neutral words, the memory advantage typically enjoyed by the emotional words sometimes disappears (Dewhurst \& Parry, 2000; Hadley \& MacKay, 2006).

A common interpretation of stimulus effects found only in mixed-list designs is that they result from item distinctiveness. For example, mixed lists are required for the observation of the effects of orthographic distinctiveness (Hunt \& Mitchell, 1982), the bizarreness effect (McDaniel \& Einstein, 1986), the humor effect (Schmidt, 1994; Schmidt \& Williams, 2001), and the greater recall of lowthan of high-infrequency words (DeLosh \& McDaniel, 1996). If emotional words are better remembered than neutral words only in mixed lists, it is tempting to attribute the putative effects of emotion to item distinctiveness (Dewhurst \& Parry, 2000).

However, before one attributes the emotional memory effect to item distinctiveness, how distinctiveness leads to

S. R. Schmidt, sschmidt@mtsu.edu 
this effect should be specified. Numerous researchers have suggested that distinctive material receives increased rehearsal (Rundus, 1971), greater depth of processing (Craik \& Lockhart, 1972), increased attention (Green, 1958), or increased individual-item processing (Hunt \& Mitchell, 1982; Schmidt, 1991), relative to common material. Thus, one interpretation of the emotional memory effect is that distinctive/emotional material receives increased processing relative to common/neutral material. This increased processing may occur only in the context of common material (Hunt \& Elliott, 1980; Schmidt, 1991), limiting the effect to mixed-list designs. Alternatively, many researchers frame the effects of distinctiveness in terms of the contrast in the memory representation between distinctive and common information, rather than in terms of differential encoding processes (Eysenck, 1979; Murdock, 1960; Neath, 1993; von Restorff, 1933). Perhaps the memory representations of emotional items stand out against the background of nonemotional material stored in memory.

Research concerning memory for emotional words is further complicated by evidence that good memory for emotional words may result from only a small subset of the words employed (Manning \& Goldstein, 1976). As compared with neutral words, words associated with sex and the bathroom were well remembered, whereas words associated with violence were remembered at the same level as the neutral words (Manning \& Goldstein, 1976). Taboo words (e.g., vulgar sexual references and racial taunts) appear to be especially potent, leading to changes in skin conductance (Walker \& Tarte, 1963) and vasoconstriction indicative of defensive responses (Maltzman et al., 1966). Kensinger and Corkin (2003) demonstrated that taboo words led to greater recognition than did both negative-affect emotional words and neutral words. In addition, taboo words more frequently led to remember responses than did negative and neutral words. Furthermore, Pesta, Murphy, and Sanders (2001) found that taboo words were less susceptible to false memories than were neutral words. Thus, taboo words may fall into the class of threatening stimuli that have special evolutionary significance. Such stimuli may lead to a fast and automatic shift of attention to the stimuli (Öhman, Flykt, \& Esteves, 2001). If this is the case, the processes responsible for the good memory for taboo and less threatening emotional stimuli may be quite different.

Evidence for differential processing of neutral, emotional, and taboo words can be found in Stroop's (1935) color-naming task. In the emotional Stroop effect, emotional words are presented in different font colors, and the participants are asked to name the color, ignoring the word. Color naming of emotional words is often slower than color naming of comparable neutral words (see Williams, Mathews, \& MacLeod, 1996, for a review). One interpretation of the emotional Stroop effect is that the emotional words lead to a preattentive response. That is, they automatically attract attention, distracting the participants from the color-naming task and, thus, increasing the time required to name the color of the emotional words, relative to the neutral words.

However, McKenna and Sharma (2004) challenged the idea that emotional words lead to a fast, preattentive re- sponse that slows color naming. They argued that in many studies of the emotional Stroop effect, words of a given type (e.g., emotional) are presented in blocks. In a homogeneous block of words, the processing of an emotional word may carry over to the presentation of the next emotional word. The long reaction times in the color naming of the emotional words may result from this relatively slow, postattentive response to the emotional words. As a test of the carryover hypothesis, McKenna and Sharma (2004) repeatedly presented either an emotional or a neutral word, followed immediately by six neutral words, and measured the colornaming times for all seven words. The next word in the series was presented immediately following the participant's response, yielding very short interstimulus intervals (ISIs). Color-naming times were equivalent for the emotional and the neutral words. However, response times were longer to stimuli following emotional words than to those following neutral words. The researchers concluded that the emotional Stroop effect resulted from a relatively slow shift in attention to the emotional word after color naming occurred, slowing color naming of the next word in the series.

McKenna and Sharma's (2004) experiments employed negative-emotion, nontaboo words (e.g., kill, fear). Other researchers have demonstrated emotional Stroop effects with random presentations and relatively long ISIs when taboo words served as the emotional stimuli (MacKay et al., 2004, Experiment 1). Thus, there appear to be two different emotional Stroop effects: the taboo Stroop effect that results from a fast preattentive processing of threatening stimuli (i.e., taboo words) and the emotional Stroop effect that results from relatively slow, voluntary, and selective attention to nonthreatening but emotionally significant stimuli.

From a differential-processing view of the effects of emotion on memory, the two different attentional responses to taboo and nontaboo emotional words should yield differences in memory performance. The fast attention response should support good memory for taboo words independently of experimental design. However, if nontaboo emotional words receive relatively slow postattentive processing, the emotional words may steal encoding processes from neutral words in the same list. Several researchers have demonstrated poor memory for material immediately following emotional stimuli in mixed lists (Ellis, Detterman, Runcie, McCarver, \& Craig, 1971; Kramer \& Schmidt, 2007; MacKay et al., 2004; Schmidt, 2002). As a result, good memory for nontaboo emotional words may be confined to mixed-list designs. In a between-list design, any carryover from the processing of an emotional word may interfere with the processing of another emotional word in the same list.

Hadley and MacKay (2006) offered a similar explanation for why the emotional memory effect is confined to mixed-list designs. They argued that the binding of emotional material to contextual cues is given greater priority than is the binding of neutral material. During rapid presentation of stimuli (e.g., in rapid serial visual presentation tasks), priority binding of taboo words delays the binding of the next word in the series. In a mixed list, memory for taboo words exceeds memory for neutral words because of impaired context binding of the neutral words. In 
Table 1

Summary of the Experimental Designs, Types of Materials, Orders of Presentation, and Interstimulus Intervals (ISIs) Employed in Experiments 1-3

\begin{tabular}{clllc}
\hline Experiment & \multicolumn{1}{c}{ Design } & \multicolumn{1}{c}{ Materials } & \multicolumn{1}{c}{ Order } & ISI (sec) \\
\hline 1A & Mixed list $^{\mathrm{a}}$ & taboo/neutral & random & \\
1B & Between list $^{\mathrm{b}}$ & taboo/neutral & N/A & 3 \\
2A & Mixed list & emotional/neutral & random/blocked & 3 \\
2B & Mixed list & emotional/neutral & random/blocked & 1 \\
3 & Between list & taboo/emotional/neutral & N/A & 1 \\
\hline
\end{tabular}

aThe same participants saw both types of items. bDifferent participants saw the different types of items. cDifferent types of items were randomly ordered during presentation. dDifferent types of items were presented in blocks of items of the same type.

a between-list design, all the taboo and neutral words in each list have equal priority, leading to equivalent recall across the two list types. Although Hadley and MacKay argued that priority-binding effects should be magnified at rapid rates of presentation, it is possible that differences in the priority given to the encoding of emotional and neutral words are operative at the relatively slow rates employed in many memory experiments.

Support for the idea that taboo words receive extra attention and that such attention supports good memory can be found in an experiment reported by MacKay et al. (2004, Experiment 1). They compared color-naming and incidental memory for a list containing taboo and neutral words. The words were presented with a relatively long ISI $(3 \mathrm{sec})$ and in random order, conditions likely to minimize any carryover from one word to the next in the series. MacKay et al. demonstrated increased color-naming times and increased memory for the taboo words relative to the neutral words, providing a link between attention and memory. However, these researchers employed a mixed-list design. Thus, it is possible that item distinctiveness effects operating at retrieval supported good memory for the taboo words.

The research presented below explored the differential attention to, and memory for, taboo, nontaboo emotional, and neutral words in an attempt to discriminate between differential processing and representational interpretations of the emotional memory effect. To this end, both mixed- and between-list designs were employed, and in the mixed lists, the words appeared in both blocked and random orders. Incidental memory performance was studied so that we could investigate attention and memory under conditions relatively free of strategic memory processes. A summary of the combinations of experimental conditions can be found in Table 1. If good memory for taboo words results from a fast attention response, we should be able to demonstrate a taboo Stroop effect and relatively good memory for taboo words independent of experimental design. Experiments $1 \mathrm{~A}$ and $1 \mathrm{~B}$ explored the taboo Stroop and memory effects in within- and between-list designs. In contrast, if nontaboo emotional words benefit from delayed elaborative processing, they should show a different pattern of Stroop and memory effects. The emotional Stroop effect should be found only with blocked stimulus presentations and relatively short ISIs. Furthermore, good memory for nontaboo emotional words should be confined to mixed lists, when increased attention to emotional words robs attention from neutral words in the same list. In mixed-list designs, the emotional memory effect should be smaller at slower rates of presentation when increased processing of emotional words is less likely to disrupt the processing of neutral words in the immediate temporal vicinity. The emotional memory effect should also disappear in mixed-list presentations that are blocked by word type. In such a list structure, the processing of each emotional word should interfere with the processing of neighboring emotional words, rather than with the processing of neutral words in the same list. Experiments $2 \mathrm{~A}$ and $2 \mathrm{~B}$ explored the effects of blocked versus random presentation and of short and long ISIs, on the emotional Stroop and emotional memory effects with nontaboo words.

Alternatively, the emotional memory effect may result from differences in item distinctiveness in the memory representation, rather than from differences in resources devoted to item encoding. This view leads one to expect that the emotional memory effect will be relatively independent of the emotional Stroop effect. Furthermore, the memory effect should be observed in both random and blocked presentations of emotional and neutral words. Finally, unlike the taboo memory effect, the emotional memory effect should not be found in a between-list design. This hypothesis was tested in Experiment 3.

\section{EXPERIMENTS 1A AND 1B}

Three specific goals were pursued in the first experiments. First, we wished to replicate the MacKay et al. (2004) study demonstrating a Stroop effect for taboo words with a long ISI and random presentation. Second, we were interested in extending the memory aspects of the MacKay et al. study by comparing memory for taboo words with memory for easily organized neutral words. And third, we wished to compare the Stroop and memory effects in a mixed-list design (Experiment 1A) with those in a between-list design (Experiment 1B). If the taboo memory effect is the result of item distinctiveness (Dewhurst \& Parry, 2000), the effect should be observed only in the mixed-list design. Alternatively, if taboo words lead to a fast automatic shift in attention and this shift in attention is responsible for good memory for the taboo words, we should observe a taboo Stroop effect and enhanced recall of taboo words in both mixed- and between-list designs.

\section{Method}

Participants. Experiment 1A was conducted during the spring semester with 34 participants recruited from the psychology research 
Table 2

Summary of Word Characteristics for Materials Used in Experiments 1-3

\begin{tabular}{|c|c|c|c|c|}
\hline \multirow[b]{3}{*}{ Characteristic } & \multicolumn{4}{|c|}{ Word Type } \\
\hline & \multirow[b]{2}{*}{ Taboo } & \multirow[b]{2}{*}{ Emotional } & \multicolumn{2}{|c|}{ Neutral } \\
\hline & & & Experiment 1 & $\begin{array}{l}\text { Experiments } \\
2 \mathrm{~A}, 2 \mathrm{~B} \text {, and } 3\end{array}$ \\
\hline Number of letters & 4.50 & 4.75 & 4.68 & 4.75 \\
\hline $\mathrm{K} \& \mathrm{~F}$ frequency ${ }^{\mathrm{a}}$ & N/A & 29.81 & 27.00 & 29.19 \\
\hline Web frequency ${ }^{b}$ & 8.16 & 18.17 & 14.42 & 17.67 \\
\hline Familiarity & 4.65 & 4.71 & 4.64 & 4.80 \\
\hline Obscenity & 2.86 & 1.23 & 1.02 & 1.02 \\
\hline Emotionality & 2.40 & 2.32 & 1.06 & 1.06 \\
\hline
\end{tabular}

aKučera and Francis (1967) frequency count. bAlta Vista count, in millions.

pool. Sixty-six students enrolled in the following summer term participated in Experiment 1B. Previous researchers have argued that, for equivalent power, between-subjects contrasts should include approximately twice the number of participants as within-subjects contrasts (Erlebacher, 1978; McDaniel \& Einstein, 1986; Schmidt, 1994). The participants received extra credit in their classes for participating in the research.

Materials. Twenty taboo words were selected from the MacKay et al. (2004) study. They defined taboo words as profanities, insults, racial slurs, or sexual references. Neutral words were selected from the clothing category in the Battig and Montague (1969) category norms. Clothing words were matched to taboo words on the basis of the number of letters, the number of syllables, and first letter. Four taboo words that were difficult to pair with clothing words served as practice words in the Stroop task. A sample of 59 participants rated the taboo, neutral, and emotional words employed in Experiments 1-3 on three dimensions: familiarity, obscenity, and emotionality. The word set was presented in random order, and each participant rated the words on a 5-point scale on each of the three attributes. A summary of the ratings data is presented in Table 2 , and a complete list of the materials can be found in the Appendix. Taboo words were rated as significantly more obscene $(M=2.86)$ than neutral words $(M=1.02)[t(58)=17.35, S E M=0.1058]$. Furthermore, the rated emotional reaction to taboo words was stronger $(M=2.40)$ than the reaction to neutral words $(M=1.06)[t(58)=12.51, S E M=$ $0.1071]$. The taboo $(M=4.65)$ and neutral $(M=4.64)$ words were rated as equally familiar $[t(58)=0.35, S E M=0.0395]$. Further comparisons were made between the taboo and the neutral words in terms of word frequency. Four of the selected taboo words are not found in the traditional word norms. However, Blair, Urland, and Ma (2002) have shown that Internet search engines produce results comparable to those of Kučera and Francis's (1967) norms. Furthermore, they reported that among the search engines, Alta Vista was most highly correlated with the Kučera and Francis norms. In Alta Vista, the average number of hits for our taboo words in the search was $8.16 \times 10^{6}$, whereas the average for our neutral words was $14.42 \times$ $10^{6}$, a difference that was not statistically significant $[t(30)=1.10$, $\left.S E M=5.69 \times 10^{6}\right]$. The experimental words were divided into two lists matched on word length, with each list containing 8 words from each category. Half of the participants in Experiment 1A saw List 1, whereas half of the participants responded to List 2. In Experiment $1 \mathrm{~B}$, the 16 taboo words were combined to form one list for one group of participants, and the 16 matched clothing words served as materials for the second group, creating the between-subjects manipulation of word type.

To ensure that our taboo and neutral words were matched on category organization and accessibility, a pilot study was conducted employing a simulated recall procedure (see Schmidt, 1996). Forty-nine students from the research pool were asked to generate words from the clothing and taboo categories. The word categories were defined for the participants, and the practice words were given as examples of category members. Approximately half of the participants were asked to list clothing words first and then, following a short break, were asked to list taboo words. The remaining participants generated words in the reverse order. The students were given $3 \mathrm{~min}$ to try to generate words from each category. The resulting recall protocols were then scored for the presence of our experimental words. The participants generated an average of 2.50 clothing words from List 1 and 2.42 from List 2 . The corresponding means for taboo words were 2.02 and 1.93. The effect of list was not significant $[F(1,46)=0.34$, $\left.M S_{\mathrm{e}}=0.897\right]$. More of our clothing words $(M=2.46$ per list $)$ were generated than taboo words $(M=1.98$ per list) $[F(1,46)=7.12$, $\left.M S_{\mathrm{e}}=0.897\right]$. These results suggest that more of our selected clothing words were accessible from category-level information than were our taboo words. It is possible that the participants were reluctant to write down taboo words on this simulated recall task. However, we assumed that any such reluctance would be equally effective at suppressing recall of taboo words on the actual recall task.

Procedure. The participants started by completing a consent form warning that some of the words might be offensive. They then completed 40 practice color-naming trials. In Experiment 1A, practice trials were conducted with 2 taboo and 2 neutral words. In Experiment $1 \mathrm{~B}$, practice trials contained 4 words of the same type as those in the experimental trials. Each practice word was presented twice in each of the five font colors (red, yellow, green, blue, and gray). Practice was followed by 160 experimental trials. In Experiment $1 \mathrm{~A}$, the experimental trials contained 8 taboo and 8 neutral words, each presented twice in each font color. In Experiment 1B, the experimental trials contained either 16 taboo or 16 neutral words in the between-subjects manipulation. Each participant received an independent random order of the experimental trials. Each trial began with a black cross in the center of a light gray screen for $1,000 \mathrm{msec}$. Next, one of the stimuli appeared in the center of the screen. The participants responded by saying the color of the word into a microphone, and a voice key measured their reaction times. A tape recorder recorded all verbal responses. After the participant's response, the screen went blank for 2,000 msec, followed by the next trial. A Dell computer running E-Prime software controlled the presentation of the stimuli and the timing of the voiced responses. Once the experimental trials were completed, the participants were asked to spend 3 min trying to recall the words from the experimental lists. The memory test was unexpected. McKenna and Sharma (2004) reported that a 1,000-msec ISI was sufficient to minimize carryover from one word to the next. In addition, the random presentation in the mixed lists (Experiment 1A) should ensure that any carryover that might occur would fall equally on taboo and neutral words.

\section{Results and Discussion}

The tape recordings of verbal responses were compared with the appropriate responses in the computer data files. The reaction times from trials on which an error was made were excluded from the analyses. The participants whose errors exceeded the average number of errors by two standard deviations were not used in the final analyses. No participants were excluded from the final analysis in Experiment 1A; 6 were excluded in Experiment 1B. A summary of the results of both experiments can be found in Table 3.

Experiment 1A. In the within-subjects design, reaction times to taboo words $(M=708.30 \mathrm{msec})$ were significantly longer than reaction times to neutral words $(M=$ $681.59 \mathrm{msec})\left[F(1,32)=40.03, M S_{\mathrm{e}}=303.12, \eta_{\mathrm{p}}^{2}=.56\right.$ $(p<.05$ was adopted for all significance tests)]. The proportion of correct color-naming responses for taboo and neutral words was equivalent $(M \mathrm{~s}=.96)[F(1,32)=0.35$, $\left.M S_{\mathrm{e}}=0.0007, \eta_{\mathrm{p}}^{2}=.01\right]$. The proportion of taboo words recalled $(M=.67)$ was significantly greater than the pro- 
portion of neutral words recalled $(M=.39)[F(1,32)=$ $\left.51.23, M S_{\mathrm{e}}=0.03, \eta_{\mathrm{p}}^{2}=.62\right]$. These results replicate those in the MacKay et al. (2004) study, showing longer reaction time to taboo words than to neutral words and superior recall of taboo words over neutral words in a mixed-list design.

We conducted several additional analyses in attempts to provide further insight into the taboo memory effect. For example, perhaps taboo words benefit from a retrieval advantage, are recalled first, and are thus less subject to output interference. However, the output position percentile for taboo words $(M=55.8 \%)$ was numerically, but not significantly, larger than the output percentile for neutral words $(M=52.2 \%)\left[F(1,32)=0.75, M S_{\mathrm{e}}=0.0290\right.$, $\left.\eta_{\mathrm{p}}^{2}=.02\right]$. Perhaps our participants were more likely to guess taboo than neutral words, inflating taboo word recall. However, intrusions were extremely rare, with numerically fewer taboo intrusions $(M=.06)$ than clothing intrusions $(M=.21)[t(33)=0.93, S E M=0.1588$, $\left.p=.36, \eta^{2}=.03\right]$.

Experiment 1B. We were concerned that the participants in the between-subjects design might habituate to taboo words over the series of 160 color-naming trials (see McKenna \& Sharma, 1995). To address this concern, the color-naming times were broken into two blocks of 80 trials. These results failed to show a significant effect of condition $\left[F(1,58)=1.56, M S_{\mathrm{e}}=23,933.20, \eta_{\mathrm{p}}^{2}=.03\right]$ or block $\left[F(1,58)=1.79, M S_{\mathrm{e}}=901.72, \eta_{\mathrm{p}}^{2}=.03\right]$. However, the condition $\times$ block interaction was significant $\left[F(1,58)=7.70, M S_{\mathrm{e}}=901.72, \eta_{\mathrm{p}}^{2}=.12\right]$. Subsequent $t$ tests demonstrated that the reaction times to taboo words in Block $1(M=729.08 \mathrm{msec})$ were significantly longer than the reaction times to neutral words in that block $(M=$ $678.65 \mathrm{msec})\left[t(58)=1.89, S E D=26.67, \eta^{2}=.06\right]$. In Block 2, reaction times to taboo words $(M=721.21 \mathrm{msec})$ did not differ significantly from reaction times to neutral words $(M=701.20 \mathrm{msec})[t(58)=0.651, S E D=30.73$, $\left.\eta^{2}=.007\right]$. As in the within-subjects design, the proportion of correct naming responses was equivalent across the taboo $(M=.97)$ and neutral $(M=.96)$ conditions $\left[F(1,58)=0.25, M S_{\mathrm{e}}=0.0009, \eta_{\mathrm{p}}^{2}=.004\right]$.

The proportion of taboo words recalled $(M=.57)$ was significantly greater than the proportion of neutral words recalled $(M=.44)[t(58)=3.12, S E D=0.0421$, $\left.\eta^{2}=.14\right]$. These results extend the taboo memory effect to a between-subjects design. To further explore the effects of experimental design, the proportion of taboo and neutral words recalled was compared across the two designs. A larger proportion of taboo words was recalled in the withinsubjects design $(M=.67)$ than in the between-subjects de$\operatorname{sign}(M=.57)\left[t(62)=2.47, S E D=0.0415, \eta^{2}=.09\right]$. In contrast, a larger proportion of neutral words was recalled in the between-subjects design $(M=.44)$ than in the within-subjects design $(M=.39)$, but this difference was not significant $\left[t(62)=1.01, S E D=0.0452, \eta^{2}=.02\right]$.

The results reported above suggest that at least two factors contribute to the taboo memory effect. Taboo words receive increased processing, as reflected in the measure of color-naming times and as reflected in the enhanced recall of taboo words in both mixed- and between-list designs. In addition, because the taboo memory effect was also larger in the mixed-list than in the between-subjects design, the results support a role of distinctiveness in the good memory for taboo words. However, it is difficult to argue that the taboo words received increased processing as a result of the contrast between the taboo and the neutral words in the mixed list. If, as compared with the between-list design, there is greater differential processing with mixed lists, one might expect a larger Stroop effect in the mixed list. In fact, the Stroop effect was marginally larger in the between-list design. The results support the idea that the taboo memory effect was larger in the mixed-list design because, in this design, the taboo words benefit from item distinctiveness effects operative during memory retrieval processes.

\section{EXPERIMENTS 2A AND 2B}

Experiment 2 was designed to explore the relation between the emotional Stroop effect and memory with negative-affect, nontaboo, emotional words. With nontaboo negative words, three possibilities come to mind. First, perhaps we will observe both the emotional Stroop and the emotional memory effects reported in Experiment 1. Such a pattern of results would support the idea that emotional stimuli capture attention and that this increased attention supports good memory for emotional stimuli.

A second possible outcome is that we will not find an emotional Stroop effect with the nontaboo emotional words and with the slow-paced, random presentation employed in Experiment 1. This finding would replicate that in McKenna and Sharma (2004). Nonetheless, the emotional words may benefit from sustained attention, and this sustained attention may support better memory for emotional than for neutral words. This sustained attention may interfere with the color naming of the next word in the series. In Experiment 2, we compared blocked and random presentations of the emotional and neutral stimuli in order to investigate these potential carryover effects on attention and memory. Blocked presentation should yield a larger Stroop effect than does a random presentation if any carryover occurs (Waters, Sayette, \& Wertz, 2003). In Experiment $2 \mathrm{~A}$, we employed the relatively long ISI $(3 \mathrm{sec})$ used in Experiment 1, and we failed to find a significant emotional Stroop effect. Experiment 2B replicated Experiment $2 \mathrm{~A}$ with a shorter ISI (1 sec) and showed evidence for sustained attention to emotional words.

Table 3

Color Naming Times and Probabilities of Recall

in Experiment 1 for Taboo and Neutral Words

\begin{tabular}{|c|c|c|c|c|}
\hline \multirow[b]{3}{*}{ Measure } & \multicolumn{4}{|c|}{ Word Type } \\
\hline & \multicolumn{2}{|c|}{ Taboo } & \multicolumn{2}{|c|}{ Neutral } \\
\hline & $M$ & $S E$ & $M$ & $S E$ \\
\hline \multicolumn{5}{|c|}{ Mixed List (Experiment 1A) } \\
\hline Naming time (msec) & 708 & 16.38 & 682 & 15.79 \\
\hline Recall & .67 & .03 & .39 & .03 \\
\hline \multicolumn{5}{|c|}{ Between List (Experiment 1B) } \\
\hline Naming time (msec) & 725 & 19.97 & 690 & 19.97 \\
\hline Recall & .57 & .03 & .44 & .03 \\
\hline
\end{tabular}


Table 4

Color Naming Times (in Milliseconds) and Probabilities of Recall in Experiments 2A (3-sec Interstimulus Interval [ISI]) and 2B (1-sec ISI) for Emotional and Neutral Words

\begin{tabular}{|c|c|c|c|c|}
\hline \multirow[b]{3}{*}{ Measure } & \multicolumn{4}{|c|}{ Word Type } \\
\hline & \multicolumn{2}{|c|}{ Emotional } & \multicolumn{2}{|c|}{ Neutral } \\
\hline & $M$ & $S E$ & $M$ & $S E$ \\
\hline \multicolumn{5}{|c|}{3 -sec ISI } \\
\hline Naming time-random & 702 & 22.26 & 706 & 18.24 \\
\hline Naming time-blocked & 712 & 21.48 & 680 & 17.60 \\
\hline Recall-random & .43 & .04 & .36 & .05 \\
\hline Recall-blocked & .42 & .04 & .33 & .04 \\
\hline \multicolumn{5}{|c|}{ 1-sec ISI } \\
\hline Naming time-random & 684 & 15.72 & 680 & 13.62 \\
\hline Naming time-blocked & 652 & 16.12 & 635 & 13.97 \\
\hline Recall-random & .32 & .03 & .24 & .03 \\
\hline Recall-blocked & .38 & .03 & .29 & .03 \\
\hline
\end{tabular}

Extra delayed processing in support of memory should impair processing of other words within the immediate temporal vicinity of the emotional words. In blocked presentation, increased attention to one emotional word would thus reduce attention for another emotional word, potentially wiping out or reducing the memory differences between emotional and neutral words. If such carryover processing is important to the emotional memory effect, there should be a larger emotional Stroop effect in blocked than in random presentation, but a smaller memory effect.

A third possibility is that the enhanced memory for nontaboo emotional words cannot be attributed to either increased immediate or delayed attention to emotional words. Rather, emotional words may be distinctive in a retrieval context that contains both emotional and neutral words. This hypothesis predicts an emotional memory effect that is independent of the emotional Stroop effect. Furthermore, emotional words should be distinctive, relative to neutral words, in both blocked and random presentations (see McDaniel \& Einstein, 1986, for an application of this logic to bizarre and common sentences).

\section{Method}

Participants. Experiment 2A was conducted with 61 participants, and Experiment 2B, conducted approximately a year later, included a new sample of 86 participants. The participants were recruited from the psychology research pool and received extra credit in their classes to participate.

Materials. Emotional words were selected from the lists used by McKenna and Sharma (2004, Experiment 1). Neutral words came from the category of clothing in the Battig and Montague (1969) category norms. Because the emotional words were longer and more frequent than the neutral words employed in Experiment 1 (see Table 2), several of the clothing words from Experiment 1 were replaced in an attempt to equate the materials. The emotional words were rated as more emotional $(M=2.32)$ than the new set of neutral words $(M=$ 1.06) $[t(58)=10.84]$, but the word frequency for emotional words ( $M=29.81)$ was equivalent to that for neutral words $(M=29.19)$ $[t(30)=0.08, S E M=7.62]$. Similarly, the rated familiarity of the neutral $(M=4.80)$ and the emotional $(M=4.71)$ words was not significantly different $[t(58)=1.95, S E M=0.0463]$. Two mixed lists were generated by assigning half of the words of each word type to each list, holding word length and frequency constant across lists. Approximately half of the participants in each experiment saw each list.
Procedure. The procedure for Experiment 2 was very similar to that for Experiment 1. For approximately half of the participants, the two word types were randomly ordered, following the procedure of Experiment 1A. Word types were presented in blocks for the remainder of the participants. In Experiment 2A, the order of the blocks was random in both the practice and the experimental trials. In Experiment $2 \mathrm{~B}$, block order was counterbalanced across participants. In Experiment $2 \mathrm{~A}$, each trial began with a $1,000-\mathrm{msec}$ fixation point, followed by the stimulus word. After the participant responded to the color of a stimulus, the screen went blank for $2,000 \mathrm{msec}$, followed by the next trial. Experiment 2B was designed with a reduced ISI to enable us to measure carryover from one stimulus word to the next. To this end, the initial fixation point was removed. In addition, two pretests were conducted, the first with a $16-\mathrm{msec}$ and the second with a 500-msec delay between the response and the presentation of the next stimulus. Unfortunately, the participants made an excessive number of errors in both pretests. We settled on a 1,000-msec interval that led to error rates similar to those observed in Experiments 1 and 2A. After every 40 trials in the random presentation and after each block in the blocked presentation, there was an extended delay of 5,000 msec. This extended delay was designed to prevent carryover from one block of trials to the next. Once the experimental trials were completed, the participants were asked to spend 3 min trying to recall the words from the experimental lists. As in Experiment 1, the memory test was unexpected.

\section{Results and Discussion}

The tape recordings and reaction time data were analyzed as in Experiment 1. The reaction time results of 7 participants were excluded because of either excessive error rates $(n=3)$ or equipment malfunctions $(n=4)$. A summary of the results appears in Table 4.

Experiment 2A (3-sec ISI). Little evidence was observed for an emotional Stroop effect in Experiment 2A, with mean color-naming times equal to $706.98 \mathrm{msec}$ for emotional words and $692.87 \mathrm{msec}$ for neutral words $\left[F(1,54)=1.55, M S_{\mathrm{e}}=3,592, \eta_{\mathrm{p}}^{2}=.028\right]$. The power to detect the 26-msec effect of word type observed in Experiment $1 \mathrm{~A}$ in this experiment exceeded .97 . In addition, the interaction between condition (blocked vs. random) and word type was not significant $\left[F(1,54)=2.58, M S_{\mathrm{e}}=3,592\right.$, $\left.\eta_{\mathrm{p}}^{2}=.046\right]$. Although the effect of word type was numerically larger for the blocked than in the random presentation (see Table 4), the effect of word type was not reliable for the blocked presentation $[t(28)=1.48, S E M=21.61, p \approx .08]$. As in Experiment 1, the proportion of correct responses for emotional $(M=.96)$ and neutral $(M=.95)$ words were equivalent $\left[F(1,52)=1.97, M S_{\mathrm{e}}=0.0006\right]$.

A larger proportion of emotional words $(M=.42)$ was recalled than of neutral words $(M=.34)[F(1,54)=5.61$, $\left.M S_{\mathrm{e}}=0.030, \eta_{\mathrm{p}}^{2}=.094\right]$. No evidence of an interaction between word type and the blocked versus random method of presentation was observed $\left[F(1,54)=0.06, M S_{\mathrm{e}}=\right.$ 0.030 ; see Table 4]. If one assumes that the emotional memory effect is confined to the random presentation condition, the power to detect the word type $\times$ presentation condition interaction was approximately $.76 .{ }^{1}$

Experiment 2B (1-sec ISI). Emotional words led to longer response times $(M=668 \mathrm{msec})$ than did neutral words $(M=658 \mathrm{msec})\left[F(1,78)=5.21, M S_{\mathrm{e}}=881, \eta_{\mathrm{p}}^{2}=\right.$ $.063]$. Emotional words $(M=.96)$ also produced a lower proportion of correct responses than did neutral words $(M=.97)\left[F(1,78)=5.19, M S_{\mathrm{e}}=0.001, \eta_{\mathrm{p}}^{2}=.062\right] . \mathrm{In}$ 
addition, random presentation led to marginally longer response times $(M=682 \mathrm{msec})$ than did blocked presentation $(M=644 \mathrm{msec})\left[F(1,78)=3.47, M S_{\mathrm{e}}=16,859, p \approx .07\right.$, $\left.\eta_{\mathrm{p}}^{2}=.043\right]$. Unfortunately, the interaction between word type and blocking condition was not significant $[F(1,78)=$ $\left.1.71, M S_{\mathrm{e}}=881, \eta_{\mathrm{p}}^{2}=.021\right]$. However, the effect of word type was significant for the blocked presentation $[t(38)=$ $2.08, S E M=8.09$ ], but not in the random presentation condition $[t(38)=0.92, S E M=4.96$; see Table 4]. These results provide evidence for attention dwell on the emotional words. That is, the emotional Stroop effect was more robust with blocked presentations and short ISIs than with random presentations or long ISIs.

In the analysis of recall in Experiment 2B, the proportion of emotional words recalled $(M=.35)$ exceeded the proportion on neutral words recalled $(M=.27)[F(1,78)=$ $\left.9.74, M S_{\mathrm{e}}=0.027, \eta_{\mathrm{p}}^{2}=.111\right]$. Once again, there was no hint of an interaction between word type and condition $\left[F(1,78)=0.101, M S_{\mathrm{e}}=0.027, \eta_{\mathrm{p}}^{2}=.001\right]$. The power to detect an interaction in which the .08 emotional memory effect was limited to only the random condition was .88 (see note 1$)$. Blocked presentation $(M=.34)$ led to marginally greater recall than did random presentation $(M=$ $.28)\left[F(1,78)=2.79, M S_{\mathrm{e}}=0.045, p<.10, \eta_{\mathrm{p}}^{2}=.035\right]$.

The recall data were reanalyzed including both Experiment $2 \mathrm{~A}$ and $2 \mathrm{~B}$ results, and treating experiment as a factor. In this analysis, there was a main effect of experiment, with recall from Experiment $2 \mathrm{~A}(M=.38)$ significantly greater than recall from Experiment $2 \mathrm{~B}(M=$ .31) $\left[F(1,132)=7.05, M S_{\mathrm{e}}=0.052, \eta_{\mathrm{p}}^{2}=.051\right]$, revealing a predictable effect of rate of presentation. Also, the proportion of emotional words recalled $(M=.39)$ was greater than the proportion of neutral words recalled $(M=$ .31) $\left[F(1,132)=14.69, M S_{\mathrm{e}}=0.029, \eta_{\mathrm{p}}^{2}=.10\right]$. Once again, there was no hint of an interaction between word type and condition $\left[F(1,132)=0.16, M S_{\mathrm{e}}=0.029\right]$, nor was there an interaction between word type and experiment $\left[F(1,132)=0.01, M S_{\mathrm{e}}=0.029\right]$. The interaction between experiment and condition also was not significant $\left[F(1,132)=1.82, M S_{\mathrm{e}}=0.052\right]$. Thus, the recall data demonstrate enhanced recall of emotional words independently of rate of presentation and blocking condition.

Experiment 2 provided evidence for an emotional Stroop effect with nontaboo words under very restricted conditions: following blocked presentation and at relatively short ISIs. This effect is in contrast to those found in Experiment 1 with taboo words, where a Stroop effect was found during random presentation and with relatively long ISIs. Nonetheless, emotional words were recalled better than neutral words in both random and blocked mixed-list presentations and at both long and short ISIs. These memory results are difficult to explain with the idea that differences in the attention directed toward emotional and neutral words support the differences in memory. A slow shift in attention to, or priority binding of, emotional words should lead to a larger memory difference between emotional and neutral words in the random presentation than in the blocked presentation. In addition, increased mnemonic processing of emotional words to the detriment of neutral words should be more evident at fast than at slow rates of presentation. Nonetheless, our results show an emotional memory effect that is independent of blocking condition and rate of presentation. One explanation of these findings is that the emotional words were distinctive in a retrieval context that contained emotional and neutral words. This possibility was explored in Experiment 3.

\section{EXPERIMENT 3}

The results of Experiments 1 and 2 led us to conclude that different attention and memory processes are directed toward taboo, nontaboo emotional, and neutral words. Experiment 3 was designed to directly compare these three types of materials. In a between-list and between-subjects manipulation of word type, participants performed a color-naming task, followed by an unexpected recall task. During the Stroop task, we employed the short ISI used in Experiment 2B. Thus, we expected a relatively large taboo Stroop effect resulting both from the preattentive response to the taboo words and from the carryover from one taboo word to the next in the series. We also expected a small but reliable emotional Stroop effect resulting from the slow attention response that carries over from one emotional word to the next. On the free recall test, we expected to replicate Experiment 1B, demonstrating greater recall of taboo than of neutral words that is a direct function of the fast-attention response.

The interesting memory comparisons were made between the emotional and the neutral words. Perhaps the good recall of emotional words results from the distinctiveness of those words in a mixed-list design. This distinctiveness hypothesis predicted that the superior recall of emotional words reported in Experiment 2 would disappear in the betweenlist design employed in Experiment 3. Furthermore, if item distinctiveness has its impact at retrieval only, the emotional Stroop effect and memory for emotional words should be independent. Alternatively, perhaps there is slow directed attention and elaboration of emotional words, an effect not reflected in the color-naming task and not sensitive to rate of presentation. This hypothesis predicts an emotional memory effect in the between-subjects manipulation of word type employed in this experiment.

\section{Method}

Participants. Experiment 3 was conducted with 129 participants. The participants were recruited from the psychology research pool and received extra credit in their classes to participate. Forty-four participants saw the emotional list, 41 participants saw the neutral list, and 44 participants saw the taboo list.

Materials. Taboo words were the same as those used in Experiment 1. Emotional and neutral words were the same as those used in Experiment 2. As a result, the three homogeneous lists were matched on word length, and the emotional and neutral lists were matched on word frequency and familiarity. The taboo word list had a lower average familiarity rating $(M=4.65)$ than did the emotional list $(M=$ 4.80) $[t(58)=3.00, S E M=0.0491]$. This difference may bias the study against showing superior memory for taboo than for neutral words. The taboo words were rated as more obscene $(M=2.86)$ than the emotional words $(M=1.23)[t(58)=16.25, S E M=0.1003]$, and the emotional words were rated as more obscene than the neutral words $(M=1.02)[t(58)=4.07, S E M=0.0509]$. The taboo $(M=$ $2.40)$ and the emotional $(M=2.32)$ words were rated as equally 
Table 5

Color Naming Times and Probabilities of Recall in

Experiment 3 for Taboo, Emotional, and Neutral Words

\begin{tabular}{|c|c|c|c|c|c|c|}
\hline \multirow[b]{3}{*}{ Measure } & \multicolumn{6}{|c|}{ Word Type } \\
\hline & \multicolumn{2}{|c|}{ Taboo } & \multicolumn{2}{|c|}{ Emotional } & \multicolumn{2}{|c|}{ Neutral } \\
\hline & $M$ & $S E$ & $M$ & $S E$ & $M$ & $S E$ \\
\hline Naming time (msec) & 728 & 13.48 & 691 & 14.14 & 658 & 13.96 \\
\hline Recall & .53 & .02 & .30 & .02 & .29 & .02 \\
\hline
\end{tabular}

emotional $[t(58)=0.77, S E M=0.0997]$, and both the taboo and the emotional words were rated as more emotional than the neutral words $(M=1.06)[t \mathrm{~s}(58)=12.94, S E M=1.091$, and $t=10.84$, $S E M=0.1167$, respectively $]$.

Procedure. The procedure for Experiment 3 closely followed that of Experiment 1B, with the exception that 1,000 msec elapsed between each response and presentation of the next stimulus word.

\section{Results and Discussion}

The results were analyzed in the same way as in the first two experiments. The data from 8 participants were excluded because of high error rates $(n=7)$ or equipment malfunctions $(n=1)$ during the color-naming task. The color-naming times and the recall results are summarized in Table 5.

In the analysis of the color-naming times, a main effect of word type was obtained, with neutral words leading to the shortest response times $(M=658 \mathrm{msec})$, followed by emotional words $(M=690 \mathrm{msec})$ and the taboo words $(M=728 \mathrm{msec})\left[F(2,122)=6.55, M S_{\mathrm{e}}=15,984, \eta_{\mathrm{p}}^{2}=\right.$ .097]. In addition, there was a main effect of block, with response times becoming longer between the first 80 trials $(M=680 \mathrm{msec})$ and the last 80 trials $(M=704 \mathrm{msec})$ $\left[F(1,122)=33.76, M S_{\mathrm{e}}=1,114.15, \eta_{\mathrm{p}}^{2}=.217\right]$. The block $\times$ word type interaction was marginally significant $\left[F(2,122)=2.65, M S_{\mathrm{e}}=1,114.15, p \approx .07, \eta_{\mathrm{p}}^{2}=.042\right]$. Examining the effect of word type more closely, responses to taboo words were significantly slower than responses to both emotional words $[t(82)=1.90, S E M=19.53]$ and neutral words $[t(83)=3.61, S E M=19.41]$. Responses to emotional words were significantly slower than responses to neutral words $[t(79)=1.66, S E M=19.87, p \approx .05]$. These results were somewhat modulated by the marginal interaction with block. The differences between taboo and neutral words were larger in Block 1 than in Block 2, replicating the results reported in Experiment 1 (however, the differences were statistically significant in both blocks). In contrast, the differences between emotional and neutral words were larger in Block 2 than in Block 1, reaching traditional levels of significance only in Block $2[t(79)=$ $1.86, S E M=19.87]$. These results support the conclusions that the taboo and emotional Stroop effects result from different processes. The taboo Stroop effect is relatively large in magnitude and is the result of a fast attention response that habituates over trials. In contrast, the smaller emotional Stroop effect is the result of a slow carryover effect that actually increases during the course of the experiment.

The results of the recall test proved equally interesting, with a significant effect of word type on the proportion of words recalled $\left[F(2,126)=43.73, M S_{\mathrm{e}}=0.0181, \eta_{\mathrm{p}}^{2}=\right.$ $.410]$. A larger proportion of taboo words $(M=.53)$ was recalled than of emotional words $(M=.30)[t(87)=7.92$, $\left.S E M=0.029, \eta^{2}=.42\right]$ and neutral words $(M=.29)$ $\left[t(83)=8.22, S E M=0.029, \eta^{2}=.45\right]$. No difference in the recall of emotional and neutral words was observed $[t(83)=0.44, S E M=0.029]$. The power to detect the .09 difference observed in the blocked, 1-sec ISI condition in Experiment 2B exceeded .99 for this test. These results support the conclusions of Experiment 1 that the taboo memory effect is still robust in a between-subjects manipulation of word type. However, they lead one to conclude that emotional (nontaboo) and neutral words are remembered equally well in between-subjects manipulations.

Waters et al. (2003) demonstrated carryover effects in the emotional Stroop task by showing that the reaction times to neutral and filler words were made longer when they were preceded by emotional words. Perhaps good memory for emotional words results, at least in part, from this dwelling of attention on the emotional stimuli. As a test of this idea, we attempted to associate good memory for a word with both immediate and delayed attention to that word. If good memory results from a fast diversion of attention that directly interferes with color naming, remembered words (word $n$ ) should have longer response times than do notremembered words. Alternatively, if memory performance results from sustained attention to a word, the word immediately following a remembered word (word $n+1$ ) should have a longer reaction time than word $n+1$ for nonremembered words. If memory and attention are independent, there should be no relation between the response times and memory performance. To test these hypotheses, the average reaction times for remembered and not-remembered words were calculated for each participant. Then, reaction times to the words following remembered and not-remembered words (word $n+1$ ) were calculated. These reaction times were used in the calculation of a 3 (word type) $\times 2$ (status: recalled vs. not recalled) $\times 2$ (word $n$ vs. word $n+1)$ ANOVA. The ANOVA revealed a significant effect of word type $\left[F(2,120)=6.00, M S_{\mathrm{e}}=32,595, \eta_{\mathrm{p}}^{2}=.091\right]$, mirroring the reaction time results reported above. There was also a significant effect of word status $[F(1,120)=10.75$, $\left.M S_{\mathrm{e}}=506.84, \eta_{\mathrm{p}}^{2}=.082\right]$, demonstrating longer reaction times for recalled words $(M=696)$ than for nonrecalled words $(M=689)$. No other main effects or interactions were significant. Table 6 presents a summary of these response times as a function of word type. Planned comparisons revealed that response times to recalled taboo words ( $M=735 \mathrm{msec}$ ) were significantly longer than response times to forgotten taboo words $(M=722 \mathrm{msec})[t(43)=$ $2.77, S E M=4.85]$. This result supports the idea that the fast attention response is associated with good memory for taboo words. In addition, response times to the word following a remembered taboo word $(M=731 \mathrm{msec})$ were significantly longer than response times to the word following forgotten taboo words $(M=721 \mathrm{msec})[t(43)=2.20$, $S E M=4.74]$, suggesting a role of sustained attention in the taboo memory effect. In contrast, with nontaboo emotional words, the response times for remembered and forgotten emotional words were equivalent $(M \mathrm{~s}=692 \mathrm{msec})$, as were the response times to words following remembered $(M=695 \mathrm{msec})$ and forgotten $(M=687 \mathrm{msec})$ emotional 
Table 6

Experiment 3 Mean Reaction Times (in Milliseconds) for Recalled and Not-Recalled Words (Word $n$ ), and for Words Following (Word $n+1)$ Recalled and Not-Recalled Words As a Function of Word Type

\begin{tabular}{|c|c|c|c|c|c|c|}
\hline \multirow[b]{3}{*}{ Words } & \multicolumn{6}{|c|}{ Word Type } \\
\hline & \multicolumn{2}{|c|}{ Taboo } & \multicolumn{2}{|c|}{ Emotional } & \multicolumn{2}{|c|}{ Neutral } \\
\hline & $M$ & $S E$ & $M$ & $S E$ & $M$ & $S E$ \\
\hline \multicolumn{7}{|c|}{ Word $n$} \\
\hline Recalled & 735 & 14.08 & 692 & 14.96 & 665 & 14.77 \\
\hline Not recalled & 722 & 13.55 & 692 & 14.39 & 655 & 14.21 \\
\hline \multicolumn{7}{|c|}{ Word $n+1$} \\
\hline Recalled & 731 & 14.31 & 695 & 15.20 & 657 & 14.01 \\
\hline Not recalled & 721 & 13.32 & 689 & 14.14 & 657 & 13.97 \\
\hline
\end{tabular}

words $[t(38)=1.17, S E M=5.39]$. Thus, good memory for taboo, but not negative-emotion, words was related to attention as measured by the color-naming task.

The results of Experiment 3 serve to further support the argument that taboo and nontaboo emotional words are processed differently. Taboo words lead to a strong and fast attention response, this response habituates over trials, and taboo words are remembered better than neutral words even in a between-subjects design. In contrast, the Stroop effect builds up across a list of emotional words, since processing one emotional word slows color naming of subsequent words. This processing has no impact on item recall, in that dwell time did not predict later recall and emotional words and neutral words were equally well recalled in the between-list design.

\section{GENERAL DISCUSSION}

At least since the time of William James (1890/1950), researchers have argued that emotional stimuli receive increased attention and that this attention is responsible for enhanced memory for emotional experiences. Others have argued that the putative effects of emotion are due to a von Restorff effect or distinctiveness (e.g., Dewhurst \& Parry, 2000; Loftus \& Burns, 1982; McCloskey et al., 1988). Recently, researchers have argued that attention and distinctiveness work together to create the complex effects of emotion on memory performance (Schmidt, 1991, 2002, 2006). However, few have investigated how or when attention and item distinctiveness contribute to these complex effects.

The three experiments reported explored attention and memory for taboo, emotional (nontaboo), and neutral words. Experiment 1 demonstrated that taboo words led to longer color-naming times and better memory than did neutral words in both mixed-list and between-list designs and at relatively long ISIs. Experiment 2 compared nontaboo emotional words with a matched list of neutral words in both random and blocked presentations. An emotional Stroop effect emerged only with block presentation and a short ISI. Nonetheless, emotional words were better remembered than neutral words, and the magnitude of this effect was the same in blocked and random presentations and at fast and slow rates of presentation. These results provided no evidence that the emotional words received extra encoding resources to the detriment of the neutral words in the same list. Experiment 3 provided a direct comparison between taboo, nontaboo emotional, and neutral words in a between-list manipulation of word type. The taboo Stroop and the taboo memory effects were observed again, and an emotional Stroop effect was observed with the nontaboo words. However, there was no evidence that the nontaboo emotional words were remembered better than the neutral words, and there was no association between color-naming times and memory for these words.

These results support the hypothesis that the taboo memory effect results from a fast shift of attentional resources toward the mnemonic processing of the taboo words. However, they also provide four independent sources of evidence that emotional nontaboo words do not receive such processing. First, the emotional words were recalled better than the neutral words under conditions that failed to show increased attention to the emotional words, as measured in the color-naming task (i.e., random presentation in Experiment 2). Second, the emotional memory effect was independent of rate of presentation. Third, the emotional memory effect was the same under blocked and random presentations. And fourth, good memory for emotional words was not associated with word decision times or with decision times to the next word in the series. These conclusions are further reinforced by the fact that our research was sensitive enough to detect differences in attention to emotional and neutral words, as measured in the color-naming task. It may not be possible to completely rule out differential processing as a source or the emotional memory effect; to do so would require proving the null hypothesis. However, the results do show that differential encoding plays a larger role in the taboo memory effect than in the emotional (nontaboo) memory effect. In contrast, item distinctiveness is relatively more important for the emotional memory effect than for the taboo memory effect. It would seem that the burden of proof would now be on those arguing that differential processing supports good recall of nontaboo emotional words.

A complete explanation of the results requires the separation of emotional words into different word types, a division of attention processes into fast and slow responses, and a complete theory of memory incorporating both encoding and retrieval processes. A three-stage model, similar to the incongruity hypothesis offered by Schmidt (1991) and to ideas developed by Christianson (1992a, 1992b) and Fabiani (2006; see also Fabiani \& Donchin, 1995), may provide an explanation. Perhaps extremely threatening stimuli (such as taboo words) lead to a fast, automatic shift in attention toward stimulus analysis and away from less significant tasks (e.g., color naming). Threatening stimuli also benefit from a second type of processing: continued attention or elaboration following stimulus presentation, leading to anterograde amnesia effects like those reported in Schmidt (2002). Less significant emotional stimuli do not lead to the fast automatic shift in attention but lead to attention dwell, or a shift in task priorities, which may influence performance on the color-naming task. However, the impact of this attention dwell on memory performance may be highly task specific and may occur only on intentional memory tasks. The third factor is item discrimina- 
tion processes operative at the time of the memory test. Both threatening and nonthreatening words stand out and are distinctive in the memory representation, supporting good memory for emotional words in mixed-list designs.

There are at least two frameworks in which one might cast the distinctiveness of emotional stimuli. In the first, emotional words are distinctive in the same way that lowfrequency words are distinctive in Eysenck's (1979) distinctiveness hypothesis. Low-frequency words were thought to appear in fewer preexperimental contexts than do frequent words, giving them greater item distinctiveness and an advantage on recognition tests. Even though the emotional and the neutral words were matched in frequency in our experiments, emotional words may generally appear in fewer different preexperimental contexts than do neutral words. That is, emotional words may have less context variability than do neutral words, and this may support better memory for the emotional words (Marsh, Meeks, Hicks, Cook, \& Clark-Foos, 2006). In this, as in other interpretations of the effects of distinctiveness (e.g., Nairne, 1990), it is the relative distinctiveness of the memory representations that supports good memory for the distinctive emotional words. As a result, good recall of emotional words will be confined to mixed-list designs. Several observations support this view. First, the effects of context variability may be larger in mixed-list than in between-list manipulations (see Hicks, Marsh, \& Cook, 2005). Second, the word frequency effect in free recall also varies with experimental design (the socalled mixed-list paradox; Watkins, LeCompte, \& Kim, 2000). In a between-list design, high-frequency words are recalled better than low-frequency words (see Gregg, 1976, for a review). However, with mixed lists, low-frequency words are sometimes recalled better than high-frequency words (DeLosh \& McDaniel, 1996; Gregg, Montgomery, \& Castaño, 1980; Saint-Aubin \& LeBlanc, 2005).

The distinctiveness of emotional experiences may also result specifically from the participants' emotional response to the material. Perhaps emotional stimuli can, under appropriate conditions, lead to both a semantic-linguistic code and a separate emotional-affective code. These emotional codes may be analogous to the imagery codes in Paivio's (1971) dual-coding framework. Like imagery codes, there is evidence that emotional coding is linked to right-hemisphere processing (Borod et al., 1998). Perhaps the emotional code serves to distinguish emotional items from nonemotional items in a shared context in the same way that the imaginal code provides for the distinctiveness of concrete words (Paivio, Walsh, \& Bons, 1994). This interpretation is also similar to Nairne's (1990) explanation of the modality effect in immediate recall. Nairne argued that modality-dependent features retained for some items served to make those items distinctive, relative to other items in a list. In the same way, perhaps emotional responses to some items in a list (but not others) provide distinctive emotional features that aid reconstruction of those items in a mixed-list design.

In summary, the results reported above make four important new contributions to our knowledge concerning the processing of emotional stimuli. First, the taboo Stroop effect and the emotional Stroop effect are different phenomena, subject to different experimental influences. Second, recall of taboo words exceeds memory for neutral words in both mixed-list and between-subjects designs. Third, this good memory for taboo words can be at least partially attributed to increased attention to these words. And fourth, as compared with taboo words, good memory for nontaboo emotional words depends much less on increased attention at encoding and more on item distinctiveness. These findings begin to specify when and how attention and distinctiveness work together to influence memory for emotional stimuli.

\section{AUTHOR NOTE}

This research was supported in part by a Faculty Research Grant from Middle Tennessee State University awarded to the first author and by a McNair Fellowship awarded to the second author. Correspondence concerning this article should be directed to S. R. Schmidt, Department of Psychology, Middle Tennessee State University, Murfreesboro, TN 37132 (e-mail: sschmidt@mtsu.edu).

\section{REFERENCES}

Battig, W. F., \& Montague, W. E. (1969). Category norms for verbal items in 56 categories: A replication and extension of the Connecticut category norms. Journal of Experimental Psychology, 80(3, Pt. 2), 1-46.

Blair, I. V., Urland, G. R., \& Ma, J. E. (2002). Using Internet search engines to estimate word frequency. Behavior Research Methods, Instruments, \& Computers, 34, 286-290.

Borod, J. C., Cicero, B. A., Obler, L. K., Welkowitz, J., Erhan, H. M., SANTSCHI, C., ET AL. (1998). Right hemisphere emotional perception: Evidence across multiple channels. Neuropsychology, 3, 446-458.

Brown, R., \& Kulik, J. (1977). Flashbulb memories. Cognition, 5, 73-99.

Christianson, S.-Å. (1992a). Emotional stress and eyewitness memory: A critical review. Psychological Bulletin, 112, 284-309.

Christianson, S.-Å. (1992b). Remembering emotional events: Potential mechanisms. In S.-A. Christianson (Ed.), The handbook of emotion and memory: Research and theory (pp. 307-340). Hillsdale, NJ: Erlbaum.

Craik, F. I. M., \& Lockhart, R. S. (1972). Levels of processing: A framework for memory research. Journal of Verbal Learning \& Verbal Behavior, 11, 671-684.

DeLosh, E. L., \& McDaniel, M. A. (1996). The role of order information in free recall: Application to the word-frequency effect. Journal of Experimental Psychology: Learning, Memory, \& Cognition, 22, 1136-1146.

Dewhurst, S. A., \& PArry, L. A. (2000). Emotionality, distinctiveness, and recollective experience. European Journal of Cognitive Psychology, 12, 541-551.

EASTERBROOK, J. A. (1959). The effect of emotion on cue utilization and the organization of behavior. Psychological Review, 66, 183-201.

Ellis, N. R., Detterman, D. K., Runcie, D., McCarver, R. B., \& CRAIG, E. (1971). Amnesic effects in short-term memory. Journal of Experimental Psychology, 89, 357-361.

Erlebacher, A. (1978). The analysis of multifactor experiments designed to contrast the within- and between-subjects manipulations of independent variables. Behavior Research Methods \& Instrumentation, 10, 833-840.

EysENCK, M. W. (1979). Depth, elaboration, and distinctiveness. In L. S. Cermak \& F. I. M. Craik (Eds.), Levels of processing in human memory (pp. 89-118). Hillsdale, NJ: Erlbaum.

Fabiani, M. (2006). Multiple electrophysiological indices of distinctiveness. In R. R. Hunt \& J. B. Worthen (Eds.), Distinctiveness and memory (pp. 339-360). Oxford: Oxford University Press.

FABiani, M., \& Donchin, E. (1995). Encoding processes and memory organization: A model of the von Restorff effect. Journal of Experimental Psychology: Learning, Memory, \& Cognition, 21, 224-240.

GreEN, R. T. (1958). The attention-getting value of structural change. British Journal of Psychology, 49, 311-314.

GREGG, V. H. (1976). Word frequency, recognition and recall. In J. Brown (Ed.), Recall and recognition (pp. 183-215). London: Wiley.

Gregg, V. H., Montgomery, D. C., \& Castaño, D. (1980). Recall of 
common and uncommon words from pure and mixed lists. Journal of Verbal Learning \& Verbal Behavior, 19, 240-245.

Hadley, C. B., \& MacKaY, D. G. (2006). Does emotion help or hinder immediate memory? Arousal versus priority-binding mechanisms. Journal of Experimental Psychology: Learning, Memory, \& Cognition, 32, 79-88.

Heuer, F., \& Reisberg, D. (1990). Vivid memories of emotional events: The accuracy of remembered minutiae. Memory \& Cognition, 18, 496-506.

Hicks, J. L., Marsh, R. L., \& CooK, G. I. (2005). An observation on the role of context variability in free recall. Journal of Experimental Psychology: Learning, Memory, \& Cognition, 31, 1160-1164.

Hunt, R. R., \& ElliotT, J. M. (1980). The role of nonsemantic information in memory: Orthographic distinctiveness effects on retention. Journal of Experimental Psychology: General, 109, 49-74.

Hunt, R. R., \& Mitchell, D. B. (1982). Independent effects of semantic and nonsemantic distinctiveness. Journal of Experimental Psychology: Human Learning \& Memory, 8, 81-87.

JAMES, W. (1950). The principles of psychology. New York: Dover. (Original work published 1890)

Kensinger, E. A., \& Corkin, S. (2003). Memory enhancement for emotional words: Are emotional words more vividly remembered than neutral words? Memory \& Cognition, 31, 1169-1180.

Kleinsmith, L. J., \& Kaplan, S. (1963). Paired-associate learning as a function of arousal and interpolated interval. Journal of Experimental Psychology, 65, 190-193.

KLeinsmith, L. J., \& Kaplan, S. (1964). Interaction of arousal and recall interval in nonsense syllable paired-associate learning. Journal of Experimental Psychology, 67, 124-126.

Kramer, D. A., \& SchmidT, S. R. (2007). Alcohol beverage cues impair memory in high social drinkers. Cognition \& Emotion, 21, 1535-1545.

KuČERA, H., \& Francis, W. N. (1967). Computational analysis of present-day American English. Providence, RI: Brown University Press.

Laney, C., Campbell, H. V., Heuer, F., \& Reisberg, D. (2004). Memory for thematically arousing events. Memory \& Cognition, 32, 1149-1159.

Loftus, E. F., \& Burns, T. E. (1982). Mental shock can produce retrograde amnesia. Memory \& Cognition, 10, 318-323.

MacKay, D. G., Shafto, M., TaYlor, J. K., Marian, D. E., Abrams, L., \& DYER, J. R. (2004). Relations between emotion, memory, and attention: Evidence from taboo Stroop, lexical decision, and immediate memory tasks. Memory \& Cognition, 32, 474-488.

Maltzman, I., Kantor, W., \& Langdon, B. (1966). Immediate and delayed retention, arousal, and the orienting and defensive reflexes. Psychonomic Science, 6, 445-446.

Manning, S. K, \& Goldstein, F. D. (1976). Recall of emotional and neutral words as a function of rate and organization of list presentation. Journal of General Psychology, 95, 241-249.

Marsh, R. L., Meeks, J. T., Hicks, J. L., CoOK, G. I., \& Clark-Foos, A (2006). Concreteness and item-to-list context associations in the free recall of items differing in context variability. Journal of Experimental Psychology: Learning, Memory, \& Cognition, 32, 1424-1430.

McCloskey, M., Wible, C. G., \& Cohen, N. J. (1988). Is there a special flashbulb-memory mechanism? Journal of Experimental Psychology: General, 117, 171-181.

McDaniel, M. A., \& Einstein, G. O. (1986). Bizarre imagery as an effective memory: The importance of distinctiveness. Journal of Experimental Psychology: Learning, Memory, \& Cognition, 12, 54-65.

McKenna, F. P., \& Sharma, D. (1995). Intrusive cognitions: An investigation of the emotional Stroop task. Journal of Experimental Psychology: Learning, Memory, \& Cognition, 21, 1595-1607.

McKenna, F. P., \& Sharma, D. (2004). Reversing the emotional Stroop effect reveals that it is not what it seems: The role of fast and slow components. Journal of Experimental Psychology: Learning, Memory, \& Cognition, 30, 382-392.
Murdock, B. B., JR. (1960). The distinctiveness of stimuli. Psychological Review, 67, 16-31.

NAIRNE, J. S. (1990). A feature model of immediate memory. Memory \& Cognition, 18, 251-269.

Neath, I. (1993). Distinctiveness and serial position effects in recognition. Memory \& Cognition, 21, 689-698.

Öhman, A., Flykt, A., \& Esteves, F. (2001). Emotion drives attention: Detecting the snake in the grass. Journal of Experimental Psychology: General, 130, 466-478.

PAIVIO, A. (1971). Imagery and verbal processes. New York: Holt, Rinehart \& Winston.

Paivio, A., Walsh, M., \& Bons, T. (1994). Concreteness effects on memory: When and why? Journal of Experimental Psychology: Learning, Memory, \& Cognition, 20, 1196-1204.

Pesta, B. J., Murphy, M. D., \& Sanders, R. E. (2001). Are emotionally charged lures immune to false memory? Journal of Experimental Psychology: Learning, Memory, \& Cognition, 27, 328-338.

Reisberg, D., \& Heuer, F. L. (2004). Memory for emotional events. In D. Reisberg \& P. Hertel (Eds.), Memory and emotion (pp. 3-41). London: Oxford University Press.

Rundus, D. (1971). Analysis of rehearsal processes in free recall. Journal of Experimental Psychology, 89, 63-77.

Saint-Aubin, J., \& LeBlanc, J. (2005). Word frequency effects in immediate serial recall of pure and mixed lists: Tests of the associative link hypothesis. Canadian Journal of Experimental Psychology, 59, 219-227.

SchmidT, S. R. (1991). Can we have a distinctive theory of memory? Memory \& Cognition, 19, 523-542.

SCHMidT, S. R. (1994). The effects of humor on sentence memory. Journal of Experimental Psychology: Learning, Memory, \& Cognition, 20, 953-967.

SCHMIDT, S. R. (1996). Category typicality effects in episodic memory: Testing models of distinctiveness. Memory \& Cognition, 24, 595-607.

SchmidT, S. R. (2002). Outstanding memories: The positive and negative effects of nudes on memory. Journal of Experimental Psychology: Learning, Memory, \& Cognition, 28, 353-361.

SchmidT, S. R. (2006). Emotion, significance, distinctiveness, and memory. In R. R. Hunt \& J. B. Worthen (Eds.), Distinctiveness and memory (pp. 47-64). Oxford: Oxford University Press.

Schmidt, S. R., \& Williams, A. R. (2001). Memory for humorous cartoons. Memory \& Cognition, 29, 305-311.

Stroop, J. R. (1935). Studies of interference in serial verbal reactions. Journal of Experimental Psychology, 18, 643-662.

TALmi, D., \& Moscovitch, M. (2004). Can semantic relatedness explain the enhancement of memory for emotional words? Memory \& Cognition, 32, 742-751.

vON RESTORFF, H. (1933). Über die Wirkung von Bereichsbildungen im Spurenfeld. Psychological Research, 18, 299-342.

WALKER, E. L., \& TARTE, R. D. (1963). Memory storage as a function of arousal and time with homogeneous and heterogeneous lists. Journal of Verbal Learning \& Verbal Behavior, 2, 113-119.

Waters, A. J., Sayette, M. A., \& Wertz, J. M. (2003). Carry-over effects can modulate emotional Stroop effects. Cognition \& Emotion, 17, 501-509.

WatKIns, M. J., LeCompte, D. C., \& Kim, K. (2000). Role of study strategy in recall of mixed lists of common and rare words. Journal of Experimental Psychology: Learning, Memory, \& Cognition, 26, 239-245.

Williams, J. M. G., Mathews, A., \& MacLeod, C. (1996). The emotional Stroop task and psychopathology. Psychological Bulletin, 120, 3-24.

\section{NOTE}

1. To estimate this value, we assumed that all the cells in the $2 \times 2$ interaction were equal to the grand mean in the experiment (e.g., $M=.384$ ), with the exception of the cell containing the mean for the emotional words in the random presentation condition. That mean was set to $.08+$ the grand mean (e.g., .464). Power was then calculated using these values to calculate the $M S$ for the interaction and the observed error term for the interaction. 
APPENDIX

Words Used in Experiments 1-3, With Alta Vista Search Hits, Kučera and Francis $(1967 ;$ K\&F) Frequency Counts, and Familiarity,

Obscenity, and Emotional Ratings

\begin{tabular}{|c|c|c|c|c|c|}
\hline Word & Alta Vista Hits & $\mathrm{K} \& \mathrm{~F}$ & Familiarity & Obscenity & Emotionality \\
\hline \multicolumn{6}{|c|}{ Clothing Words } \\
\hline Apron & $1,950,000$ & 7 & 4.53 & 1.00 & 1.05 \\
\hline Belt* & $14,800,000$ & 29 & 4.88 & 1.04 & 1.09 \\
\hline Boots & $13,300,000$ & 13 & 4.84 & 1.02 & 1.04 \\
\hline Cap & $22,500,000$ & 27 & 4.75 & 1.00 & 1.05 \\
\hline Coat & $11,100,000$ & 43 & 4.81 & 1.00 & 1.02 \\
\hline Dress & $21,100,000$ & 67 & 4.88 & 1.02 & 1.09 \\
\hline Fur $^{\dagger}$ & $5,830,000$ & 56 & 4.58 & 1.04 & 1.19 \\
\hline Jacket* & $10,600,000$ & 33 & 4.77 & 1.04 & 1.04 \\
\hline Nylons ${ }^{\dagger}$ & 964,000 & 0 & 4.49 & 1.04 & 1.02 \\
\hline Parka $^{\dagger}$ & 340,000 & 0 & 3.42 & 1.02 & 1.00 \\
\hline Purse & $4,590,000$ & 14 & 4.81 & 1.16 & 1.05 \\
\hline Robe & $2,530,000$ & 6 & 4.65 & 1.00 & 1.02 \\
\hline Shirt & $24,000,000$ & 27 & 4.81 & 1.00 & 1.09 \\
\hline Shoes & $30,900,000$ & 44 & 5.00 & 1.00 & 1.12 \\
\hline Shorts & $8,460,000$ & 29 & 4.82 & 1.07 & 1.00 \\
\hline Skirt & $5,490,000$ & 21 & 4.77 & 1.02 & 1.11 \\
\hline Slip & $13,200,000$ & 19 & 4.63 & 1.00 & 1.04 \\
\hline Socks & $7,760,000$ & 7 & 4.88 & 1.02 & 1.05 \\
\hline Watch & $90,400,000$ & 81 & 4.86 & 1.00 & 1.11 \\
\hline \multicolumn{6}{|c|}{ Emotional Words } \\
\hline Abuse & $32,300,000$ & 18 & 4.65 & 1.58 & 3.00 \\
\hline Angry & $14,800,000$ & 45 & 4.81 & 1.09 & 2.39 \\
\hline Cancer & $30,300,000$ & 25 & 4.75 & 1.12 & 2.89 \\
\hline Crash & $18,500,000$ & 20 & 4.79 & 1.12 & 1.95 \\
\hline Doom & $12,500,000$ & 3 & 4.48 & 1.09 & 2.02 \\
\hline Fail & $20,400,000$ & 37 & 4.75 & 1.11 & 2.23 \\
\hline Grief & $6,520,000$ & 10 & 4.74 & 1.11 & 2.07 \\
\hline Guilt & $5,520,000$ & 33 & 4.75 & 1.11 & 2.07 \\
\hline Hate & $31,000,000$ & 42 & 4.82 & 1.71 & 3.12 \\
\hline Kill & $37,000,000$ & 63 & 4.68 & 1.77 & 2.89 \\
\hline Misery & $4,110,000$ & 15 & 4.53 & 1.21 & 2.12 \\
\hline Pain & $37,700,000$ & 88 & 4.91 & 1.12 & 2.35 \\
\hline Panic & $8,360,000$ & 22 & 4.65 & 1.09 & 2.19 \\
\hline Rage & $8,890,000$ & 16 & 4.56 & 1.33 & 2.58 \\
\hline Shock & $18,300,000$ & 31 & 4.67 & 1.14 & 1.74 \\
\hline Sorrow & $4,530,000$ & 9 & 4.67 & 1.09 & 2.21 \\
\hline \multicolumn{6}{|c|}{ Taboo Words } \\
\hline Anus & $1,100,000$ & & 4.47 & 2.14 & 1.65 \\
\hline Bitch & $11,000,000$ & 6 & 4.89 & 3.18 & 2.75 \\
\hline Chink & 215,000 & & 3.86 & 2.74 & 2.28 \\
\hline Cock & $13,100,000$ & 5 & 4.47 & 3.50 & 2.34 \\
\hline Dick & $20,200,000$ & 18 & 4.65 & 2.70 & 2.07 \\
\hline Dildo & $5,090,000$ & & 4.46 & 2.42 & 1.79 \\
\hline Dyke & $2,220,000$ & 1 & 4.35 & 2.65 & 2.20 \\
\hline Fuck & $20,700,000$ & 4 & 4.86 & 3.73 & 2.91 \\
\hline Nigger & 452,000 & 12 & 4.49 & 4.05 & 3.19 \\
\hline Piss & $4,480,000$ & 1 & 4.67 & 2.32 & 1.74 \\
\hline Pussy & $13,400,000$ & 5 & 4.61 & 3.54 & 2.58 \\
\hline Queer & $3,250,000$ & 6 & 4.61 & 2.47 & 2.44 \\
\hline Rape & $8,470,000$ & 5 & 4.58 & 2.23 & 3.47 \\
\hline Shit & $16,200,000$ & 2 & 4.81 & 2.74 & 1.86 \\
\hline Slut & $5,630,000$ & & 4.75 & 2.65 & 2.42 \\
\hline Whore & $5,120,000$ & 2 & 4.65 & 2.72 & 2.53 \\
\hline
\end{tabular}

*Words used only in Experiments 1A and 1B. †Words replacing the words marked by an asterisk in Experiments 2A, 2B, and 3.

(Manuscript received October 24, 2006;

revision accepted for publication March 21, 2007.) 